\title{
The action of chemical and mechanical stresses on single and dual species biofilm removal of drinking water bacteria
}

\author{
I.B. Gomes ${ }^{\text {a }}$, M. Lemos ${ }^{\text {a }}$, L. Mathieu ${ }^{\mathrm{b}}$, M. Simões ${ }^{\mathrm{a}}$, L.C. Simões ${ }^{\mathrm{a}, \mathrm{c}, *}$ \\ a LEPABE, Department of Chemical Engineering, Faculty of Engineering, University of Porto, Rua Dr. Roberto Frias, s/n, 4200-465 Porto, Portugal \\ ${ }^{\mathrm{b}}$ EPHE, Laboratory of Physical Chemistry and Microbiology for the Environment, UMR 7564 CNRS-Université de Lorraine, Nancy, France \\ c CEB-Centre of Biological Engineering, University of Minho, Campus de Gualtar, 4710-057 Braga, Portugal
}

\section{H I G H L I G H T S}

- The removal of opportunistic bacteria was assessed with a rotating cylinder reactor.

- Dual species biofilms were the most susceptible to chemical and mechanical removal.

- Pretreatment with $\mathrm{NaOCl}$ did not improve the impact of mechanical stress.

- S. maltophilia biofilms demonstrated high tolerance to $\mathrm{NaOCl}$ and mechanical stress.

\section{A R T I C L E I N F O}

\section{Article history:}

Received 7 December 2017

Received in revised form 29 January 2018

Accepted 5 March 2018

Available online $\mathrm{xxxx}$

Editor: Paola Verlicchi

\section{Keywords:}

Biofilm removal

Drinking water

Rotating cylinder reactor

Shear stress

Sodium hypochlorite
G R A P H I C A L A B S T R A C T

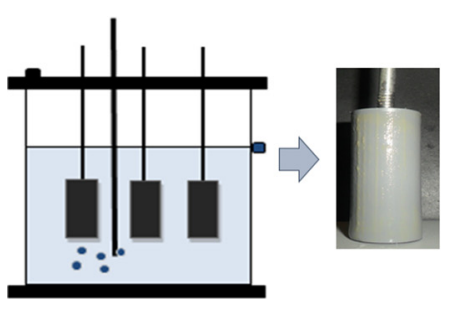

Biofilm removal in drinking water distribution systems

\begin{abstract}
A B S T R A C T
The presence of biofilms in drinking water distribution systems (DWDS) is a global public health concern as they can harbor pathogenic microorganisms. Sodium hypochlorite $(\mathrm{NaOCl})$ is the most commonly used disinfectant for microbial growth control in DWDS. However, its effect on biofilm removal is still unclear. This work aims to evaluate the effects of the combination of chemical $(\mathrm{NaOCl})$ and mechanical stresses on the removal of single and dual species biofilms of two bacteria isolated from DWDS and considered opportunistic, Acinectobacter calcoaceticus and Stenotrophomonas maltophilia. A rotating cylinder reactor was successfully used for the first time in drinking water biofilm studies with polyvinyl chloride as substratum. The single and dual species biofilms presented different characteristics in terms of metabolic activity, mass, density, thickness and content of proteins and polysaccharides. Their complete removal was not achieved even when a high $\mathrm{NaOCl}$ concentrations and an increasing series of shear stresses (from 2 to $23 \mathrm{~Pa}$ ) were applied. In general, NaOCl pre-treatment did not improve the impact of mechanical stress on biofilm removal. Dual species biofilms were colonized mostly by S. maltophilia and were more susceptible to chemical and mechanical stresses than these single species. The most efficient treatment (93\% biofilm removal) was the combination of $\mathrm{NaOCl}$ at $175 \mathrm{mg} \cdot \mathrm{l}^{-1}$ with mechanical stress against dual species biofilms. Of concern was the high tolerance of S. maltophilia to chemical and mechanical stresses in both single and dual species biofilms. The overall results demonstrate the inefficacy of $\mathrm{NaOCl}$ on biofilm removal even when combined with high shear stresses.
\end{abstract}

(c) 2018 Elsevier B.V. All rights reserved.

\footnotetext{
* Corresponding author at: CEB-Centre of Biological Engineering, University of Minho, Campus de Gualtar, 4710-057 Braga, Portugal.

E-mail address: luciachaves@deb.uminho.pt (L.C. Simões).
}

\section{Introduction}

Biofilm formation is one of the main microbiological concerns in drinking water (DW) quality management. In fact, about $95 \%$ of the total biomass in water is attached to pipe walls, while the remaining is in the bulk phase (Wingender and Flemming, 2004). Biofilms are 
formed by microorganisms attached to a surface and embedded in a polymeric matrix, which they own excrete. Microorganisms that live embedded in biofilms enjoy more advantages than those in planktonic state (Mathieu et al., 2016; Simões and Simões, 2013). The extracellular polymeric substances (EPS) have an important role in microbial survival under undesirable environmental conditions. The matrix of EPS is able to capture and concentrate environmental nutrients and increases biofilm resistance to antimicrobial agents and mechanical stresses (Simões et al., 2005; Simões and Simões, 2013; Xue et al., 2012). Another significant advantage of the biofilm mode of growth is the potential for dispersion by detachment (Stewart, 2012). Following the direction of the fluid, detached biofilm portions travel to other regions and promote biofilm formation on clean areas (Codony et al., 2005). Moreover, biofilms can act as reservoir of pathogenic organisms and influence directly bacterial density and diversity in the bulk phase due to detachment (Wingender and Flemming, 2011). Therefore, the presence of biofilms in drinking water distribution systems (DWDS) is a global concern that can influence the DW quality and hence the public health. Consequently, DW treatment is a necessary process to ensure high standards of quality (WHO, 2011). Chemical disinfection, based on nonspecific oxidative processes to inactivate microorganisms is conventionally used to treat DW (Simões and Simões, 2013). Chlorination is the predominant disinfection method used in DWDS as it is a low cost process, easy to apply and is effective in the inactivation of a wide variety of pathogenic microorganisms (Donnermair and Blatchley III, 2003). The residual concentration of free chlorine in DWDS should be maintained under values lower than $1 \mathrm{mg} \cdot \mathrm{l}^{-1}$ and nearer $0.5 \mathrm{mg} \cdot \mathrm{l}^{-1}$ (WHO, 2011). However, this residual concentration appears not to be enough to prevent the growth and development of microbial biofilms (O'Flaherty et al., 2017; Su et al., 2018; Zhou et al., 2009). Although, it can inactivate the majority of planktonic bacteria (LeChevallier et al., 1998). A recent work described the effects of sodium hypochlorite $(\mathrm{NaOCl})$ on DW biofilm killing and removal (Gomes et al., 2016). High biofilm killing rates were achieved. However, even extreme $\mathrm{NaOCl}$ concentrations had reduced biofilm removal efficacy, allowing biofilm reseed. Therefore, complementary strategies are required for effective biofilm control (killing and removal) in DWDS (Gomes et al., 2016).

Pipe flushing, a mechanical treatment, is already used to control chemical and biological deposits in DWDS (Husband and Boxall, 2011). This is one of the least expensive techniques used to maintain DWDS microbiologically safe (Simões and Simões, 2013). It consists in the replacement of contaminated water by clean one through high velocity flow in pipes. This procedure can remove the sludge and sediments from pipe walls, eliminate tastes and odors, reduce turbidity and restore the disinfectant residual concentration, affording a better prevention of microbial regrowth (Antoun et al., 1999; Friedman et al., 2002). Usually, it is applied at large-scale as periodic preventive measure or as response to localized water quality problems (Antoun et al., 1999; Friedman et al., 2002; Husband and Boxall, 2011). As chemical disinfection at in-use concentrations in DWDS is not efficient in biofilm control from pipe surfaces, the combination of chlorination and pipe flushing represents complementary strategies of potential interest to control biofilms in DWDS.

The aim of this work was to understand the behavior of single and dual species biofilms of Acinetobacter calcoaceticus and Stenotrophomonas maltophilia to chemical and mechanical stresses, complementing a first study on the action of $\mathrm{NaOCl}$ on DW biofilm control (Gomes et al., 2016). A. calcoaceticus and S. maltophilia were used as model microorganisms. These bacteria are recognized as opportunistic and were already associated to infections related to hospital water supply (Cervia et al., 2008; Gales et al., 2001; Pal and Kale, 1981; Vincenti et al., 2014). Furthermore, polyvinyl chloride (PVC) was selected as substratum for biofilm formation due to its broad use in DWDS (Gomes et al., 2016). Biofilms were formed on PVC surfaces in a rotary cylinder reactor, a bench top laboratorial device that allows the testing of well- defined single or combined chemical and mechanical strategies on biofilm control (Simões et al., 2009).

\section{Material and methods}

\subsection{Bacteria and culture conditions}

A. calcoaceticus and S. maltophilia were isolated from a DWDS (Simões et al., 2007). Bacterial cells were grown overnight in batch cultures using a concentrated nutrient medium $\left(5 \mathrm{~g} \cdot \mathrm{l}^{-1}\right.$ glucose, $2.5 \mathrm{~g} \cdot \mathrm{l}^{-1}$ peptone, $1.25 \mathrm{~g} \cdot \mathrm{l}^{-1}$ yeast extract (Merck, VWR, Portugal) and $0.2 \mathrm{M}$ phosphate buffer at $\mathrm{pH} 7)$ at room temperature $\left(23 \pm 3{ }^{\circ} \mathrm{C}\right)$ and under agitation (120 rpm) in an orbital incubator (New Brunswick Scientific, I26, USA).

\subsection{Substratum}

PVC was used as substratum for biofilm formation and was selected as a representative pipe material from DW networks (Simões et al., 2007). Before biofilm formation PVC cylinders were immersed in a solution of commercial detergent (Sonasol Pril, Henkel Ibérica S. A.). In order to remove any remaining detergent, the cylinders were rinsed in distilled sterile water and subsequently immersed in ethanol at 70\% $\left(\mathrm{v} \cdot \mathrm{v}^{-1}\right)$ for $5 \mathrm{~min}$. Afterwards they were rinsed three times with distilled sterile water and dried at $60{ }^{\circ} \mathrm{C}$ for $3 \mathrm{~h}$, before being used for biofilm assays.

\subsection{Rotating cylinder reactor - experimental set-up}

A rotating cylinder reactor was used to grow biofilms on PVC cylinders (Simões et al., 2005, 2009) (Fig. 1) with a surface area of $34.6 \mathrm{~cm}^{2}$ (diameter $=2.2 \mathrm{~cm}$; length $=5.0 \mathrm{~cm}$ ) inserted in a 51 vessel and maintaining a constant shear stress of 1 Pa through the use of shaftdrive agitators (Heidolph, Germany). Three PVC cylinders, prepared as referred before, were used in every experiment. The 51 vessel was inoculated with $250 \mathrm{ml}$ of $10^{8} \mathrm{CFU} \cdot \mathrm{ml}^{-1}$ of A. calcoaceticus or S. maltophilia in the stationary growth phase, being afterwards continuously fed with sterile diluted nutrient medium $\left(0.05 \mathrm{~g} \cdot \mathrm{l}^{-1}\right.$ glucose, $0.025 \mathrm{~g} \cdot \mathrm{1}^{-1} \mathrm{pep}$ tone, $0.0125 \mathrm{~g} \cdot \mathrm{l}^{-1}$ yeast extract and $0.2 \mathrm{M}$ phosphate buffer at $\mathrm{pH}$ 7) at a constant rate $\left(0.5 \mathrm{l} \cdot \mathrm{h}^{-1}\right)$ in order to enforce bacterial adhesion instead of planktonic growth. For dual species biofilm formation the reactor was inoculated with $125 \mathrm{ml}$ of $10^{8} \mathrm{CFU} \cdot \mathrm{ml}^{-1}$ of each bacterium. The biofilms were allowed to grow for $7 \mathrm{~d}$ in order to obtain steady-state biofilms (Simões et al., 2005). After 7 days of continuous operation the single and dual species biofilms on the PVC cylinders were carefully immersed in $0.2 \mathrm{M}$ phosphate buffered saline (PBS) at $\mathrm{pH} 7$ to remove loosely attached cells. Then, the biofilms were characterized and tested on their behavior to chemical and mechanical treatments.

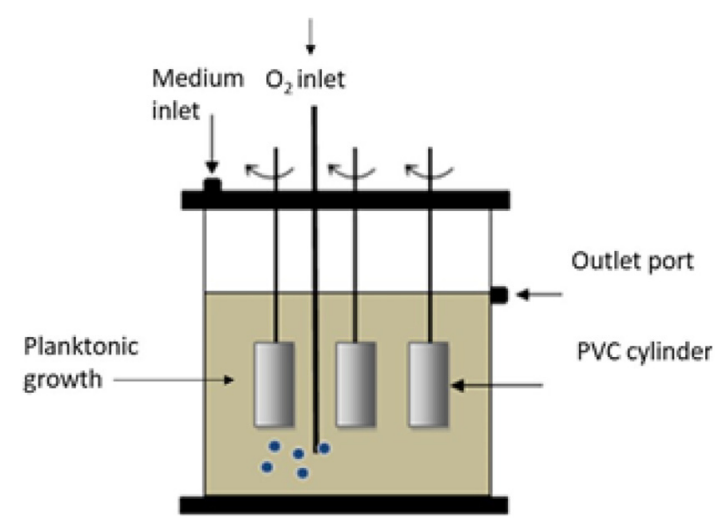

Fig. 1. Sectional view of the rotary cylinder reactor used to grow the $7 \mathrm{~d}$ old single and dua species biofilms. 


\subsection{Biofilm sampling for characterization}

Biofilms were characterized in terms of thickness, wet and dry mass, respiratory activity, density, culturable cells and EPS content. Biofilm thickness was determined using a digital micrometer (VS-30H, Mitsubishi Kasei Corporation) according to Teodósio et al. (2011). Wet biofilm mass was obtained by measuring the weight of the cylinder with and without biofilm. Biofilm density was assessed as the ratio between the biofilm dry mass and thickness.

To assess the other biofilm characteristics (dry biomass, respiratory activity, cell density and EPS content) the biofilms were removed from the cylinders using a stainless steel scraper and resuspended in $10 \mathrm{ml}$ of extraction buffer $\left(0.76 \mathrm{~g} \cdot 1^{-1} \mathrm{Na}_{3} \mathrm{PO}_{4} \cdot \mathrm{H}_{2} \mathrm{O}, 0.36 \mathrm{~g} \cdot \mathrm{l}^{-1} \mathrm{Na}_{2} \mathrm{HPO}_{4} \cdot \mathrm{H}_{2} \mathrm{O}\right.$, $\left.0.53 \mathrm{~g} \cdot \mathrm{l}^{-1} \mathrm{NaCl}, 0.08 \mathrm{~g} \cdot \mathrm{l}^{-1} \mathrm{KCl}\right)$. Afterwards, the biofilm suspensions were homogenized by vortexing (30 s, 100\%) as described by Simões et al. (2005, 2009). Biofilm respiratory activity was determined using a YSI 5300A Biological Oxygen Monitor according to Simões et al. (2009). The total and extracellular polymeric substances (in terms of proteins and polysaccharides content) were quantified after extraction with Dowex® Marathon $\odot$ resin $\left(\mathrm{NA}^{+}\right.$form, strongly acidic, 20-50 mesh, Sigma) according to Frølund et al. (1996). Dowex resin was added to the biofilm suspension in a $25 \mathrm{ml}$ beaker and the extraction took place for $4 \mathrm{~h}$ at $400 \mathrm{rpm}$ and $4{ }^{\circ} \mathrm{C}$. The extracellular components present in the supernatant were separated from cells through centrifugation ( $3700 \mathrm{~g}, 5 \mathrm{~min}$ ). The biofilm proteins were quantified by the Lowry modified method (Sigma) using bovine serum albumin as standard (Lowry et al., 1951; Peterson, 1979). The polysaccharides were quantified using the phenol-sulphuric method using glucose as standard (Dubois et al., 1951).

The dry biofilm mass was assessed by determination of the total volatile solids (TVS) which are equivalent to the amount of biological mass. The homogenized biofilm suspensions were placed in a furnace at 550 $\pm 5{ }^{\circ} \mathrm{C}$ for $2 \mathrm{~h}$ (WEF, 1989). The biofilm mass accumulated was expressed in $\mathrm{mg}$ of biofilm per $\mathrm{cm}^{2}$ of surface area of the cylinder.

The number of culturable bacteria was assessed in terms of colony forming units (CFU) on plate count agar (PCA, Merck, VWR). After biofilm scraping from PVC surface, the suspension was diluted to the adequate cellular concentration in $0.2 \mathrm{M}$ phosphate buffer before plating. For dual species biofilms the number of CFU per $\mathrm{cm}^{2}$ was also assessed for each bacterium. This was possible because these bacteria had clear distinct colony morphologies. Colony enumeration was carried out after $24 \mathrm{~h}$ incubation at $23 \pm 3{ }^{\circ} \mathrm{C}$.

Three independent experiments were performed for biofilm characterization.

\subsection{Biofilm chemical removal}

The cylinders plus biofilm were removed from the reactor, washed in phosphate buffer to remove weakly or non-adherent bacteria and subsequently were immersed in $300 \mathrm{ml}$ glass flasks containing $\mathrm{NaOCl}$ (Sigma) dissolved in $0.2 \mathrm{M}$ phosphate buffer. Two conditions were tested: $\mathrm{NaOCl}$ at $0.5 \mathrm{mg} \cdot \mathrm{l}^{-1}$ and at the minimum inhibitory concentration determined in a previous work (Gomes et al., 2016): $125 \mathrm{mg} \cdot \mathrm{l}^{-1}$ for A. calcoaceticus biofilms, $175 \mathrm{mg} \cdot \mathrm{l}^{-1}$ for S. maltophilia biofilms and dual species biofilms. The control (untreated biofilm) was carried out with $0.2 \mathrm{M}$ phosphate buffer instead of $\mathrm{NaOCl}$. Biofilm exposure to $\mathrm{NaOCl}$ solutions was carried out at constant shear stress ( $1 \mathrm{~Pa}$, the same used for biofilm formation) for $30 \mathrm{~min}$ (Lemos et al., 2015). After treatment, the disinfectant solutions were removed and the biofilms on the PVC cylinders were rinsed twice by immersion in $0.5 \%(\mathrm{w} / \mathrm{v})$ sodium thiosulfate (Merck, VWR) for $10 \mathrm{~min}$ to quench the activity of the disinfectant and finally one time in $0.2 \mathrm{M}$ phosphate buffer. Afterwards, the wet mass of biofilm was assessed to characterize biofilm removal due to $\mathrm{NaOCl}$ exposure, and the cylinders plus biofilms were then used for experiments on mechanical removal. Three independent experiments were performed for each condition tested.

\subsection{Biofilm mechanical removal}

The cylinders plus biofilm were exposed to increasing shear stresses according to Simões et al. (2005). After chemical treatment, cylinders plus biofilm were inserted in $300 \mathrm{ml}$ glass flasks with $0.2 \mathrm{M}$ phosphate buffer and consecutively subjected to increasing shear stresses $(2,7$, 14 and $23 \mathrm{~Pa}$ ) for $30 \mathrm{~s}$ each. Table 1 presents the hydrodynamic conditions in the reactor (Reynolds number, velocity of rotation, velocity of fluid on the cylinder surface and the shear stress on the cylinder surface).

Eq. (1) was used to assess shear stress (Altman et al., 2009):

$\tau_{s}=\frac{f \cdot \rho \cdot v^{2}}{2}$

where $\tau_{s}(\mathrm{~Pa})$ is the shear stress, $f$ is the fanning factor and $v$ is the average velocity $\left(\mathrm{m} \cdot \mathrm{s}^{-1}\right)$. The Fanning factor for a rotating cylinder is given by Eq. (2) as described by Gabe and Walsh (1983) and the velocity $\left(\mathrm{m} \cdot \mathrm{s}^{-1}\right)$ is given by the Eq. (3).

$f=0.158 R e_{A}^{-0.3}$

$v=N \cdot \pi \cdot D$

$R e_{A}=\frac{D^{2} N \rho}{\mu}$

where $R e_{A}$ is the Reynolds number of agitation, $D(\mathrm{~m})$ is the diameter of the cylinder, $N\left(\mathrm{~s}^{-1}\right)$ is the rotation speed, $\rho\left(\mathrm{Kg} \cdot \mathrm{m}^{-3}\right)$ is the fluid density and $\mu\left(\mathrm{Kg} \cdot \mathrm{m}^{-1} \cdot \mathrm{s}^{-1}\right)$ is the fluid viscosity (Geankoplis, 1993).

The wet weight of the cylinder plus biofilm attached was determined before and after each exposure to a different shear stress.

The wet mass of the biofilm that was removed from the cylinder surface after each shear stress exposure was expressed as percentage of biofilm removal (Eq. (5)). The biofilm removed after the chemical treatment or after the exposure to the complete series of shear stress were assessed according to Eq. (6). The amount of biofilm remaining adhered after exposure to chemical and mechanical treatments was expressed as percentage of biofilm remaining according to Eq. (7) (Simões et al., 2005, 2009).

Biofilm removal by individual shear stress $(\%)_{i}=\frac{X_{i}-X_{j}}{X_{\text {biofilm }}} \times 100$

Overall mechanical or chemical biofilm removal $(\%)=\frac{X_{i}-X_{j}}{X_{i}} \times 100$

Biofilm remaining $\%=\frac{X_{\text {remaining }}}{X_{\text {biofilm }}} \times 100$

where $X_{\text {biofilm }}$ corresponds to the total biofilm mass formed on the PVC cylinder before the treatments (chemical and mechanical), $X_{i}$ is the biofilm mass before chemical or mechanical treatment $(i), X_{j}$ is the biofilm mass after chemical or mechanical treatment $(i)$, and $X_{\text {remaining }}$

Table 1

Hydrodynamic conditions in the RCR used for biofilm formation and during the chemical and mechanical treatments. The values were assessed through Eqs. (1)-(4).

\begin{tabular}{lllll}
\hline & $\begin{array}{l}\text { Rotation } \\
\text { speed } \\
\left(N-\mathrm{s}^{-1}\right)\end{array}$ & $\begin{array}{l}\text { Reynolds } \\
\text { number } \\
(R e)\end{array}$ & $\begin{array}{l}\text { Fluid } \\
\text { velocity } \\
(v-\mathrm{m} / \mathrm{s})\end{array}$ & $\begin{array}{l}\text { Shear } \\
\text { stress } \\
(\tau-\mathrm{Pa})\end{array}$ \\
\hline Biofilm formation & 4.97 & 2400 & 0.34 & 1 \\
Chemical treatment & 4.97 & 2400 & 0.34 & 1 \\
Mechanical treatment & 8.27 & 4000 & 0.57 & 2 \\
(increasing shear stress) & 16.73 & 8100 & 1.16 & 7 \\
& 25.00 & 12,100 & 1.73 & 14 \\
& 33.27 & 16,100 & 2.30 & 23
\end{tabular}


Table 2

Characteristics of $7 \mathrm{~d}$ old A. calcoaceticus and S. maltophilia single and dual species biofilms. Results represent the average of three independent assays and respective standard deviation.

\begin{tabular}{|c|c|c|c|}
\hline & A. calcoaceticus & S. maltophilia & Dual species \\
\hline \multicolumn{4}{|l|}{ Biofilm mass $\left(\mathrm{mg} \cdot \mathrm{cm}^{-2}\right)$} \\
\hline Wet & $1.33 \pm 0.12$ & $0.67 \pm 0.13$ & $0.59 \pm 0.08$ \\
\hline Dry & $0.06 \pm 0.0 \mathrm{l}$ & $0.041 \pm 0.003$ & $0.07 \pm 0.01$ \\
\hline Biofilm density $\left(\mathrm{mg} \cdot \mathrm{cm}^{-3}\right)$ & $7.8 \pm 0.7$ & $10.3 \pm 2.0$ & $7.9 \pm 1.5$ \\
\hline Thickness $(\mu \mathrm{m})$ & $180 \pm 70$ & $64 \pm 22$ & $74 \pm 8.3$ \\
\hline $\log \mathrm{CFU} \cdot \mathrm{cm}^{-2}$ & $7.3 \pm 0.09$ & $7.7 \pm 0.3$ & $7.4 \pm 0.6^{\mathrm{a}}$ \\
\hline \multicolumn{4}{|l|}{ Proteins $\left(\mathrm{mg} \cdot \mathrm{g}_{\text {biofilm }}^{-1}\right)$} \\
\hline Extracellular & $60.4 \pm 6.8$ & $36.6 \pm 15$ & $19.4 \pm 6.0$ \\
\hline Total & $168 \pm 36$ & $144 \pm 13$ & $94.5 \pm 35$ \\
\hline \multicolumn{4}{|l|}{ Polysaccharides (mg $\cdot \mathrm{g}_{\text {biofilm }}^{-1}$ ) } \\
\hline Extracellular & $166 \pm 51$ & $153.7 \pm 37$ & $110.6 \pm 18$ \\
\hline Total & $244 \pm 88$ & $206.5 \pm 54$ & $138.7 \pm 26$ \\
\hline $\begin{array}{l}\text { Biofilm respiratory activity } \\
\left(\mathrm{mg} \mathrm{O}_{2} \cdot \text { g }_{\text {biofilm }}^{-1} \cdot \mathrm{min}^{-1}\right)\end{array}$ & $0.248 \pm 0.08$ & $0.056 \pm 0.007$ & $2.490 \pm 0.877$ \\
\hline
\end{tabular}

corresponds to the biofilm mass remaining adhered on the PVC cylinder after exposure to all the treatments.

Three independent experiments were performed for each condition tested.

\subsection{Statistical analysis}

Data was analyzed using One-Way ANOVA test from the statistical software SPSS 20.0 (Statistical Package for the Social Sciences). The comparisons between and within experimental groups were carried out using Tukey test. Statistical calculations were based on a confidence level $\geq 95 \%$, assuming a significance level for the separation set at $P<0.05$.

\section{Results}

\subsection{Biofilm characterization}

The biofilms were characterized in terms of mass content, density, thickness, CFU $\cdot \mathrm{cm}^{-2}$, EPS amount and metabolic activity (Table 2). The single and dual species biofilms had similar CFU $\cdot \mathrm{cm}^{-2}(P>0.05)$. The assessment of the relative colonization revealed that dual species biofilms were mostly colonized by S. maltophilia ( $94 \%$ of the CFU $\cdot \mathrm{cm}^{-2}$ ). In terms of metabolic activity, A. calcoaceticus biofilms were about 4.4 times more active than S. maltophilia biofilms. However, dual species biofilms were 10 times more active than these of $A$. calcoaceticus $(P<0.05)$. Biomass production was higher for dual biofilms followed by $A$. calcoaceticus. Biofilms formed by $A$. calcoaceticus were significantly thicker $(P<0.05)$ than these formed by S. maltophilia and dual species biofilms. The denser biofilms were produced by $S$. maltophilia $(P<0.05)$. The other biofilms had equivalent densities $(P>0.05)$. All the biofilms had high water content: 95\% (A. calcoaceticus); 94\% (S. maltophilia); 88\% (dual species).

The EPS content was assessed for extracellular proteins and polysaccharides. A. calcoaceticus formed biofilms with higher content of extracellular proteins than the other biofilms $(P<0.05)$. The amount of polysaccharides was similar for all the biofilms $(P>0.05)$. Nevertheless, dual species biofilms produced lower amounts of total and extracellular proteins and polysaccharides than single species biofilms, even if not statistically significant $(P>0.05)$. Moreover, the content of extracellular proteins represent 36\% (A. calcoaceticus), 26\% (S. maltophilia) and 21\% (dual species) of the total proteins. In terms of extracellular polysaccharides, the values are higher: 68\% (A. calcoaceticus), 74\% (S. maltophilia) and $80 \%$ (dual species).

\subsection{Biofilm removal by $\mathrm{NaOCl}$}

A. calcoaceticus biofilms were more susceptible to removal than these of $S$. maltophilia $(P<0.05)$ when exposed to $0.5 \mathrm{mg} \cdot \mathrm{l}^{-1} \mathrm{NaOCl}$ for $30 \mathrm{~min}$ (removal of $23 \%$ for A. calcoaceticus and $8 \%$ for S. maltophilia) (Fig. 2). The use of higher $\mathrm{NaOCl}$ concentrations increased single species biofilm removal from the PVC surface, being removal of both $A$. calcoaceticus and $S$. maltophilia single species biofilms similar $(P>0.05)$ (33\% for A. calcoaceticus and 35\% for S. maltophilia). Dual species biofilm were shown to be more susceptible to $0.5 \mathrm{mg} \cdot 1^{-1} \mathrm{NaOCl}$ ( $32 \%$ of biofilm removal) than the single species biofilms $(P<0.05)$. The treatment with the highest $\mathrm{NaOCl}$ concentration did not increase dual species biofilm removal $(P>0.05)$.

\subsection{Biofilm removal by shear stress alone and combined with $\mathrm{NaOCl}$}

\subsubsection{Shear stress}

The biofilms had distinct behavior to mechanical treatment when exposed to shear stresses of 2, 7, 14 and $23 \mathrm{~Pa}$ (Fig. 3). A. calcoaceticus biofilms were more susceptible to removal when exposed to intermediate shear stresses (7 Pa caused 20\% while 14 Pa caused 18\%). Shear stresses of 2 and $23 \mathrm{~Pa}$ only caused 10\% and 9\% biofilm removal,

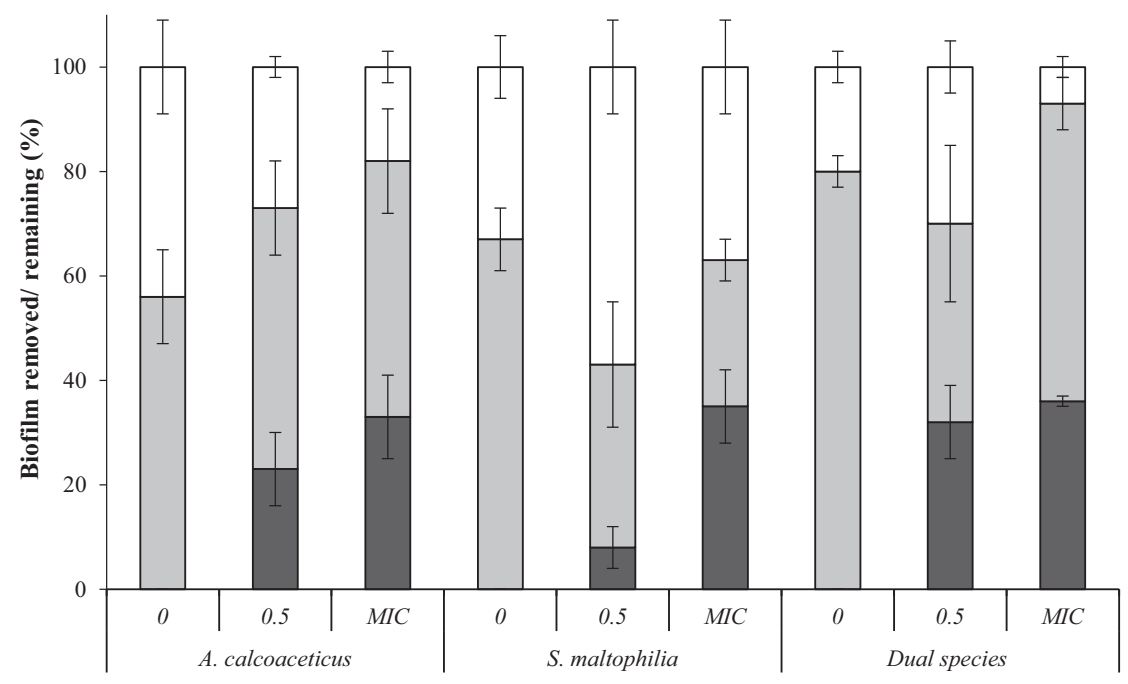

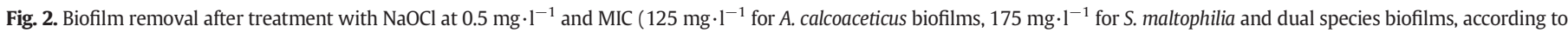

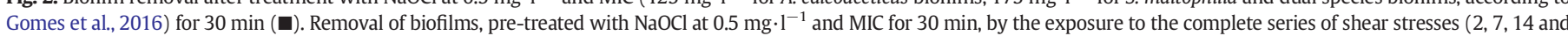
$23 \mathrm{~Pa})(\square)$. Biofilm remaining on the PVC surface after the combined chemical and the mechanical treatments ( $\square$ ). 

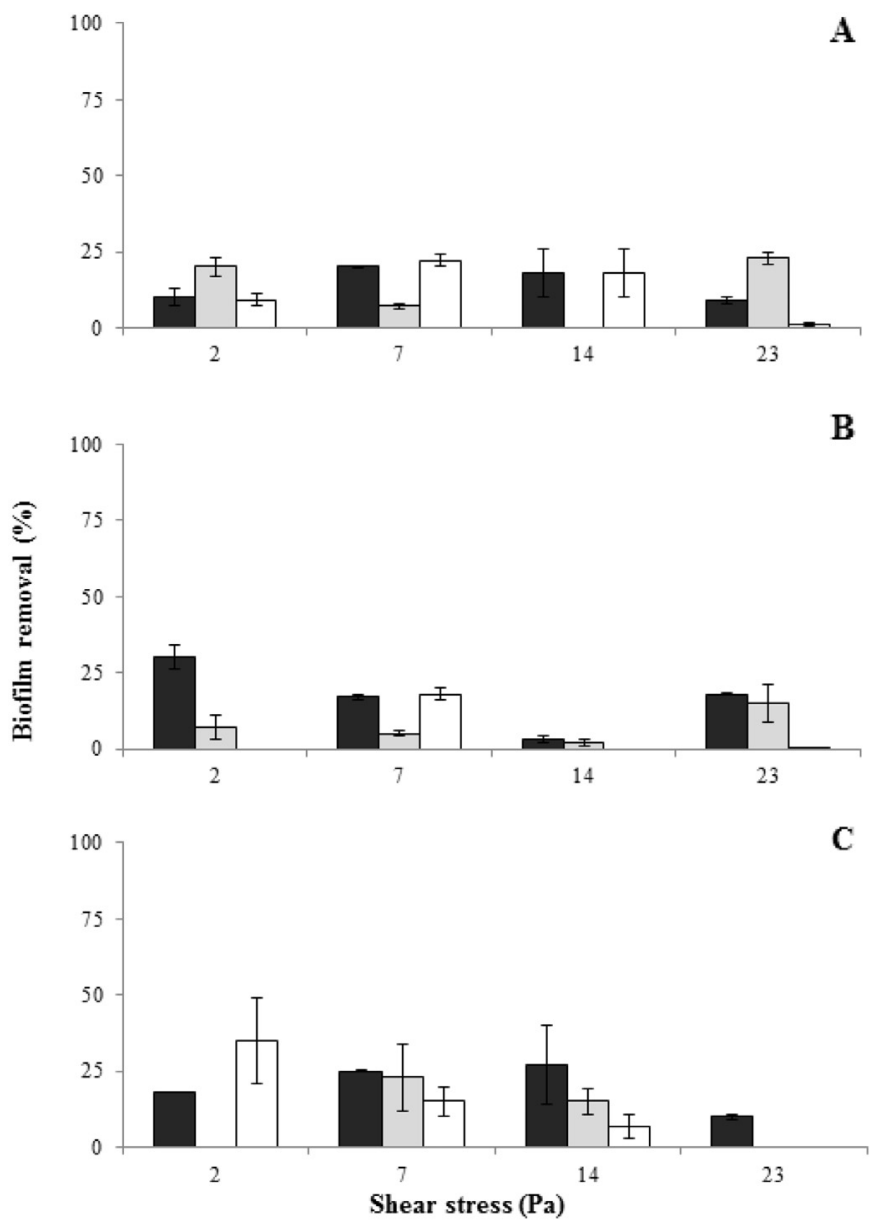

Fig. 3. Mechanical biofilm removal from PVC cylinders due to exposure to a series of increasing shear stress conditions of the biofilms previously treated with $\mathrm{NaOCl}$. A A. calcoaceticus biofilms; B - S. maltophilia biofilms; C - Dual species biofilms. $0 \mathrm{mg} \cdot \mathrm{l}^{-1}-0.5 \mathrm{mg} \cdot \mathrm{l}^{-1}$; $\square$ - MIC $\left(125 \mathrm{mg} \cdot \mathrm{l}^{-1}\right.$ for A. calcoaceticus biofilms; $175 \mathrm{mg} \cdot \mathrm{l}^{-1}$ for S. maltophilia and dual species biofilms, according Gomes et al., 2016). Results represent the average of three independent assays and respective standard deviation.

respectively (Fig. 3A). Therefore, the increasing series of shear stress removed $56 \%$ of the total biofilm (Fig. 2).

For S. maltophilia biofilms, the highest removal was caused by $2 \mathrm{~Pa}$ (30\%) and decreased with increasing shear stress to $7 \mathrm{~Pa}$. The lowest removal percentage was attained with $14 \mathrm{~Pa}(3 \%)$. A shear stress of $23 \mathrm{~Pa}$ increased again S. maltophilia biofilm removal (18\%) (Fig. 3B). The overall mechanical removal of S. maltophilia biofilms was 67\% (Fig. 2).

Dual species biofilms were more susceptible to the intermediate shear stresses, 7 (25\% removal) and $14 \mathrm{~Pa}(27 \%)$, than for the lowest (18\% removal) and highest (10\% removal) (Fig. 3C). In this case, the mechanical treatment removed $80 \%$ of the biofilm mass (Fig. 2 ).

\subsubsection{Shear stress combined with $\mathrm{NaOCl}$}

The pre-treatment of A. calcoaceticus biofilms with the residual concentration of $\mathrm{NaOCl}$ slightly increased biofilm removal with 2 and $23 \mathrm{~Pa}$ $(P<0.05)$ (Fig. 3A). Furthermore, removal decreased with exposure to 7 and $14 \mathrm{~Pa}$. For this latter shear stress, no removal was observed. The mechanical treatment after exposure to $0.5 \mathrm{mg} \cdot \mathrm{l}^{-1} \mathrm{NaOCl}$ removed $50 \%$ of the total biofilm from the PVC surface (Fig. 2). The chemical ( $0.5 \mathrm{mg} \cdot \mathrm{l}^{-1}$ $\mathrm{NaOCl}$ ) and mechanical treatments caused $73 \%$ biofilm removal (Fig. 2 ). The pre-treatment with $\mathrm{NaOCl}$ at MIC caused biofilm removal similar to the mechanical stress alone for 2,7 and $14 \mathrm{~Pa}(P>0.05)$. A decreased biofilm removal (1\%) was observed with $23 \mathrm{~Pa}$. The series of shear stress conditions caused $49 \%$ biofilm removal (Fig. 2 ). However, even after the chemical (with $\mathrm{NaOCl}$ at $\mathrm{MIC}$ ) and mechanical treatments $18 \%$ biofilm remained on the surface (Fig. 2).

The pre-treatment of $S$. maltophilia biofilms using $0.5 \mathrm{mg} \cdot \mathrm{1}^{-1} \mathrm{NaOCl}$ increased resistance to removal with 2 and 7 Pa compared to the mechanical treatment alone $(P<0.05)$ (Fig. 3B). No significant differences were observed without and with $\mathrm{NaOCl}$ pre-exposure for 14 and $23 \mathrm{~Pa}$ $(P>0.05)$. After exposure to the series of shear stress, $35 \%$ of the S. maltophilia biofilm was removed (Fig. 2). The chemical and mechanical treatments caused $43 \%$ biofilm removal (Fig. 2). The use of $\mathrm{NaOCl}$ at MIC significantly increased S. maltophilia biofilm resistance to removal by mechanical stress. In fact, only 7 Pa caused significant biofilm removal $(P<0.05)$ (Fig. 3B). The overall mechanical removal of the biofilm after chemical treatment at MIC was $28 \%$ (Fig. 2). Moreover, $37 \%$ of the biofilm remained on the PVC surface after the overall chemical (NaOCl at MIC) and mechanical treatments (Fig. 2). This combination did not cause significant removal compared to the mechanical action alone $(P>0.05)$.

No significant advantage was observed from the use of $0.5 \mathrm{mg} \cdot \mathrm{1}^{-1}$ $\mathrm{NaOCl}$ to remove dual species biofilms. Biofilm removal was always lower than when using mechanical stress alone. In fact, no removal was found when the biofilms were exposed to 2 and $23 \mathrm{~Pa}(P<0.05)$. For this case, the overall removal due to mechanical treatment was $38 \%$ (Fig. 2), and the combined action removed $70 \%$ of the biofilm (Fig. 2). With the use of $\mathrm{NaOCl}$ at MIC, only 2 Pa caused higher removal than use of mechanical stress alone. For the other conditions biofilm removal was lower than without $\mathrm{NaOCl}$ pre-exposure, particularly with $23 \mathrm{~Pa}$, where no removal was observed $(P<0.05)$. After exposure to the series of shear stresses $57 \%$ of dual species biofilm was removed. The combination of $\mathrm{NaOCl}$ at MIC and mechanical stress increased biofilm removal to $93 \%$.

\section{Discussion}

Biofilms in DWDS are responsible for several undesirable effects in the quality of the distributed water. The increased biofilm resistance to conventional disinfection processes and the increasing awareness on the public health effects of disinfection by-products clearly proposes that novel means of DW disinfection and biofilm control are needed (Meireles et al., 2016). As the levels of chlorine usually employed in DWDS are not sufficient to prevent the growth and development of microbial biofilms (Zhou et al., 2009) new and more efficient strategies are needed. Pipe flushing is regarded as a green and attractive strategy for biofilm removal (Mathieu et al., 2014; Paul et al., 2012), which can be used alone or in combination with chlorine to control biofilms in DWDS. In this study, two opportunistic bacteria, A. calcoaceticus and S. maltophilia, isolated from a DWDS were used for biofilm formation and control experiments. A rotating cylinder reactor was used for the first time in DW biofilm studies. This bench top laboratorial reactor was already successfully used in studies of chemical and mechanical control of industrial biofilms (Lemos et al., 2015; Simões et al., 2005, 2009). PVC is commonly found in DWDS and was used as model substratum for biofilm formation (Lemos et al., 2015; Simões et al., 2007).

Most studies on biofilm control with $\mathrm{NaOCl}$ focus on its effects on bacterial viability (Almatroudi et al., 2016; Simões et al., 2010). However, it is recognized that biofilm inactivation and removal are distinct phenomena. In fact, one can inactivate a biofilm without causing its removal from the surface (Gomes et al., 2016). The biofilm left on the surface can easily reseed a new one by several mechanisms: working as a conditioning film for new surface colonizers; acting as a source of nutrients for new microorganisms; recovery of sublethaly injured bacteria; dispersal to neighbor surfaces (Chambless et al., 2006). Therefore, this study focus on the study of chemical and mechanical removal of biofilms from PVC surfaces. The results showed that exposure to $\mathrm{NaOCl}$ at a residual concentration caused a maximum biofilm removal of $32 \%$ (dual species biofilms). Surprisingly, only $8 \%$ removal was found for S. maltophilia biofilms. A recent study reinforces the resilient 
properties of S. maltophilia biofilms. It was demonstrated that $24 \mathrm{~h}$ old $S$. maltophilia were more resistant to killing by $\mathrm{NaOCl}$ than A. calcoaceticus biofilms and their dual species biofilms (Gomes et al., 2016).

The shear stress values tested in the present study complements previous reports about mechanical removal of biofilms (Husband and Boxall, 2011; Mathieu et al., 2014; Neilands et al., 2012). It is clear that biofilm removal is not proportional to the shear stress increase. The high resistance to removal could be due to the stratified structure of biofilms. Simões et al. (2009) using Bacillus cereus and Pseudomonas fluorescens, recognized as significant food industry contaminants, already proposed that biofilms formed in the rotating cylinder reactor are stratified in a layered structure with each layer having differential tolerance to chemical and mechanical stresses. The near-surface layers were always more tolerant to the stress conditions (Simões et al., 2009).

The pretreatment with $\mathrm{NaOCl}$ changed biofilms resistance to mechanical removal depending on the bacterium. In fact, S. maltophilia and dual species biofilms were more tolerant to hydrodynamic stress after the chemical treatment. Even if disinfectants can weaken the biofilm structure (Davison et al., 2010; Tachikawa et al., 2009; Xavier et al., 2005) increased removal is expected to occur when challenging the biofilms with mechanical stress. $\mathrm{NaOCl}$ is a multi-target biocide and is recommended for DW disinfection (Gomes et al., 2016; Simões and Simões, 2013). However, even when high $\mathrm{NaOCl}$ concentrations were combined with high shear stress, complete biofilm removal was not achieved. This highlights the current limitations of the available disinfectants for effective biofilm control (Malheiro et al., 2016). In fact, a disinfectant effective in biofilm killing does not mean that it is effective in biofilm removal. In this study, the pretreatment with $\mathrm{NaOCl}$ did not improve the efficiency of mechanical treatment for most of the scenarios tested. Mathieu et al. (2014) have shown that an increase in the hydrodynamic constraints leads to the doubling of the number of contact points. Douterelo et al. (2013) found that flushing did not completely remove bacteria from pipe walls and generated more compact biofilms. Therefore, the first treatment (exposure to $\mathrm{NaOCl}$ ) may easily remove the less cohesive top layers, remaining on the PVC surface the layers more tolerant to adverse external conditions. Unexpectedly, S. maltophilia biofilms that had lower mass and were thinner than the other biofilms were the hardest to be removed. Therefore, S. maltophilia biofilms were not only significantly resistant to chemical inactivation (Gomes et al., 2016) but also to the mechanical stress. Moreover, the biofilm characterization also propose that the high density, CFU content and low respiratory activity of $S$. maltophilia biofilms may also account for the increased tolerance to $\mathrm{NaOCl}$ and mechanical stress. Conversely, in addition to the high respiratory activity values, it seems that the lower contents of proteins and polysaccharides (total and extracellular) help to explain the highest susceptibility of dual species biofilms.

Most of the studies propose that multispecies biofilms are more resistant than these single species. However, these studies only assess biofilm killing (Burmølle et al., 2006, 2014; Lindsay et al., 2002). This study shows that dual species association was not advantageous in protecting the biofilm from the chemical and mechanical stress conditions. Dual species biofilms were more susceptible to removal by chemical and mechanical treatments alone and combined. The presence of S. maltophilia in a significantly higher extent in dual species biofilms was not advantageous in increasing resistance to removal. Lemos et al. (2015), using the rotating cylinder reactor with stainless steel and polymethyl methacrylate surfaces for biofilm formation, also found that the association of $B$. cereus and $P$. fluorescens did not increase biofilm resistance to chemical and mechanical treatments. These biofilms were treated with the quaternary ammonium compound benzyldimethyldodecyl ammonium chloride. However, Simões et al. (2009) found that dual species biofilms of B. cereus and P. fluorescens were more resistant to chemical and mechanical stresses, using a quaternary ammonium compound (cetyl trimethyl ammonium bromide) and an aldehyde biocide (glutaraldehyde). These results in conjugation with the present ones clearly propose that multispecies biofilm resistance to removal may depend on the colonizing microorganisms, the conditions under which biofilms are formed and the type of biocide. In fact, Simões et al. (2005) tested seven distinct biocides for $P$. fluorescens biofilm removal and found that in addition of the inefficacy of the chemical treatments in biofilm removal, some biocides increased biofilm mechanical stability.

\section{Conclusion}

The overall results demonstrate the suitability of the rotating cylinder reactor to study biofilm formation and control using DW-isolated bacteria. The results also demonstrated the limited efficiency of $\mathrm{NaOCl}$ on the removal of single and dual species biofilms, even when the chemical treatment was combined with hydrodynamic stress. Dual species biofilms were more susceptible to chemical and mechanical removal than these single species. Of concern was the behavior of S. maltophilia. This bacterium is considered an emergent pathogen and may constitute a concern for DWDS maintenance and safety. In fact, S. maltophilia biofilms demonstrated to be tolerant to chemical and mechanical stresses, even when exposed to a high concentration of $\mathrm{NaOCl}$ and high shear stresses. These results reinforce the limited action of current DW disinfection strategies for biofilm control.

\section{Funding}

This work was the result of the project:

(i) POCI-01-0145-FEDER-006939 (Laboratory for Process Engineering, Environment, Biotechnology and Energy - UID/EQU/00511/ 2013) funded by the European Regional Development Fund (ERDF), through COMPETE2020 - Programa Operacional Competitividade e Internacionalização (POCI) and by national funds, through FCT - Fundação para a Ciência e a Tecnologia.

(ii) NORTE-01-0145-FEDER-000005 - LEPABE-2-ECO-INNOVATION, supported by North Portugal Regional Operational Programme (NORTE 2020), under the Portugal 2020 Partnership Agreement, through the European Regional Development Fund (ERDF).

(iii) Grants attributed by Portuguese Foundation for Science and Technology - FCT - to Inês Gomes (SFRH/BD/103810/2014) and Lúcia Simões (SFRH/BPD/81982/2011).

\section{Disclosure statement}

The authors declare no conflict of interest.

\section{References}

Almatroudi, A., Gosbell, I.B., Hu, H., Jensen, S.O., Espedido, B.A., Tahir, S., Glasbey TO, Legge, P., Whiteley, G., Deva, A., et al., 2016. Staphylococcus aureus dry-surface biofilms are not killed by sodium hypochlorite: implications for infection control. J. Hosp. Infect. 93, 263-270.

Altman, S.J., McGrath, L.K., Souza, C.A., Murton, J.K., Camper, A.K., 2009. Integration and decontamination of Bacillus cereus in Pseudomonas fluorescens biofilms. J. Appl. Microbiol. 107, 287-299.

Antoun, E.N., Dyksen, J., Hiltebrand, D.J., 1999. Unidirrectional flushing: a powerful tool. J. Am. Water Works Assoc. 91, 62-71.

Burmølle, M., Webb, J.S., Rao, D., Hansen, L.H., Sorensen, S.J., Kjelleberg, S., 2006. Enhanced biofilm formation and increased resistance to antimicrobial agents and bacterial invasion are caused by synergistic interactions in multispecies biofilms. Appl. Environ. Microbiol. 72, 3916-3923.

Burmølle, M., Ren, D., Bjarnsholt, T., Sorensen, S.J., 2014. Interactions in multispecies biofilms: do they actually matter? Trends Microbiol. 22, 84-91.

Cervia, J.S., Ortolano, G.A., Canonica, F.P., 2008. Hospital tap water as a source of Stenotrophomonas maltophilia infection. Clin. Infect. Dis. 46, 1485-1487.

Chambless, J.D., Hunt, S.M., Stewart, P.S., 2006. A three-dimensional computer model of four hypothetical mechanisms protecting biofilms from antimicrobials. Appl. Environ. Microbiol. 72, 2005-2013.

Codony, F., Morató, J., Mas, J., 2005. Role of discontinuous chlorination on microbial production by drinking water biofilms. Water Res. 39, 1896-1906. 
Davison, W.M., Pitts, B., Stewart, P.S., 2010. Spatial and temporal patterns of biocide action against Staphylococcus epidermidis biofilms. Antimicrob. Agents Chemother. 54, 2920-2927.

Donnermair, M.M., Blatchley III, E.R., 2003. Disinfection efficacy of organic chloramines. Water Res. 37, 1557-1570.

Douterelo, I., Sharpe, R.L., Boxall, J.B., 2013. Influence of hydraulic regimes on bacteria community structure and composition in an experimental drinking water distribution system. Water Res. 47, 503-516.

Dubois, M., Gilles, K., Hamilton, J.K., Rebers, P.A., Smith, F., 1951. A colorimetric method for the determination of sugars. Nature $168,167$.

Friedman, M., Kirmeyer, G.J., Antoun, E., 2002. Developing and implementing a distribution system flushing program. J. Am. Water Works Assoc. 94, 48-56.

Frølund, B., Palmgren, R., Keiding, K., Nielsen, P.H., 1996. Extraction of extracellular polymers from activated sludge using a cation exchange resin. Water Res. 30, 1749-1758

Gabe, D.R., Walsh, F.C., 1983. The rotating cylinder electrode: a review of development J. App. Electrochem. 13, 3-21.

Gales, A.C., Jones, R.N., Forward, K.R., Liñares, J., Sader, H.S., Verhoef, J., 2001. Emerging importance of multidrug-resistant Acinetobacter species and Stenotrophomonas maltophilia as pathogens in seriously ill patients: geographic patterns, epidemiological features, and trends in the SENTRY antimicrobial surveillance program (1997-1999). Clin. Infect. Dis. 32, S104-S113.

Geankoplis, C.J., 1993. Transport process and unit operations. Prentice-Hall International, New Jersey.

Gomes, I.B., Simões, M., Simões, L.C., 2016. The effects of sodium hypochlorite against selected drinking water-isolated bacteria in planktonic and sessile states. Sci. Total Environ. 565, 40-48.

Husband, P.S., Boxall, J.B., 2011. Asset deterioration and discolouration in water distribution systems. Water Res. 45, 113-124.

LeChevallier, M., Norton, C., Camper, A., Morin, P., Ellis, B., Jones, W., Rompré, A., Prevost M., Coallier, J., Servais, P., et al., 1998. Microbial impact of biological filtration. AWWA Research Foundation, USA.

Lemos, M., Gomes, I., Mergulhão, F., Melo, L., Simões, M., 2015. The effects of surface type on the removal of Bacillus cereus and Pseudomonas fluorescens single and dual species biofilms. Food Bioprod. Process. 93, 234-241.

Lindsay, D., Brozel, V.S., Mostert, J.F., von Holy, A., 2002. Differential efficacy of a chlorine dioxide-containing sanitizer against single species and binary biofilms of a dairyassociated Bacillus cereus and a Pseudomonas fluorescens isolate. J. Appl. Microbiol. 92, 352-361.

Lowry, O.H., Rosebrough, N.J., Farr, A.L., Randall, R.J., 1951. Protein measurement with the Folin phenol reagent. J. Biol. Chem. 193, 265-275.

Malheiro, J., Gomes, I., Borges, A., Bastos, M.M.S.M., Maillard, J.Y., Borges, F., Simões, M., 2016. Phytochemical profiling as a solution to palliate disinfectant limitations. Biofouling 32, 1007-1016

Mathieu, L., Bertrand, I., Abe, Y., Angel, E., Block, J.C., Skali-Lami, S., Francius, G., 2014. Drinking water biofilm cohesiveness changes under chlorination or hydrodynamic stress. Water Res. 55, 175-184.

Mathieu, L., Francius, G., El Zein, R., Angel, E., Block, J.C., 2016. Bacterial repopulation of drinking water pipe walls after chlorination. Biofouling 32, 925-934.

Meireles, A., Giaouris, E., Simões, M., 2016. Alternative disinfection methods to chlorine for use in the fresh-cut industry. Food Res. Int. 82, 71-85.

Neilands, K., Bernats, M., Rubulis, J., 2012. Accumulation and modeling of particles in drinking water pipe fittings. Drink Water Eng Sci. 5, 47-57.

O'Flaherty, E., Borrego, C.M., Balcázar, J.L., Cummis, E., 2018. Human exposure assessment to antibiotic-resistant Escherichia coli through drinking water. Sci. Total Environ. 616$617,1356-1364$
Pal, R., Kale, V., 1981. Acinetobacter calcoaceticus - an opportunistic pathogen. J. Postgrad. Med. 27, 218-221.

Paul, E., Ochoa, J.C., Pechaud, Y., Liu, Y., Liné, A., 2012. Effect of shear stress and growth conditions on detachment and physical properties of biofilms. Water Res. 46, $5499-5508$

Peterson, G.L., 1979. Review of the folin phenol protein quantitation method of Lowry, Rosebrough, Farr and Randall. Anal. Biochem. 100, 201-220.

Simões, L.C., Simões, M., 2013. Biofilms in drinking water: problems and solutions. RSC Adv. 3, 2520-2533.

Simões, M., Pereira, M.O., Vieira, M.J., 2005. Effect of mechanical stress on biofilms challenged by different chemicals. Water Res. 39, 5142-5152.

Simões, L.C., Simões, M., Oliveira, R., Vieira, M.J., 2007. Potential of the adhesion of bacteria isolated from drinking water to materials. J. Basic Microbiol. 47, 174-183.

Simões, M., Simões, L.C., Vieira, M.J., 2009. Species association increases biofilm resistance to chemical and mechanical treatments. Water Res. 43, 229-237.

Simões, L.C., Simões, M., Vieira, M.J., 2010. Influence of the diversity of bacterial isolates from drinking water on resistance of biofilms to disinfection. Appl. Environ. Microbiol. 76, 6673-6679.

Stewart, P.S., 2012. Mini-review: convection around biofilms. Biofouling 28, 187-198.

Su, H.C., Liu, Y.S., Pan, C.G., Chen, J., He, L.Y., Ying, G.G., 2018. Persistence of antibiotic resistance genes and bacterial community changes in drinking water treatment system: from drinking water source to tap water. Sci. Total Environ. 616-617, 453-461.

Tachikawa, M., Yamanaka, K., Nakamuro, K., 2009. Studies on the disinfection and removal of biofilms by ozone water using an artificial microbial biofilm system. Ozone Sci. Eng. 31, 3-9.

Teodósio, J.S., Simões, M., Melo, L.F., Mergulhao, F.J., 2011. Flow cell hydrodynamics and their effects on $E$. coli biofilm formation under different nutrient conditions and turbulent flow. Biofouling 27, 1-11.

Vincenti, S, Quaranta, G. De Meo, C. Bruno, S, Ficarra, M.G., Carovillano, S., Ricciardi, W. Laurenti, P., 2014. Non-fermentative gram-negative bacteria in hospital tap water and water used for haemodialysis and bronchoscope flushing: prevalence and distribution of antibiotic resistant strains. Sci. Total Environ. 499, 47-54.

WEF AA, 1989. Standard methods for the examination of water and wastewater. American Public Health Association/American Water Works Association/Water Environment Federation, Washington DC, USA.

WHO, 2011. Guidelines for drinking water quality. 4th ed. World Health Organization, Geneva, Switzerland.

Wingender, J., Flemming, H.C., 2004. Contamination potential of drinking water distribution network biofilms. Water Sci. Technol. 49, 277-286.

Wingender, J., Flemming, H.C., 2011. Biofilms in drinking water and their role as reservoir for pathogens. Int. J. Hyg. Environ. Health 214, 417-423.

Xavier, J.B., Picioreanu, C., Rani, S.A., van Loosdrecht, M.C., Stewart, P.S., 2005. Biofilmcontrol strategies based on enzymic disruption of the extracellular polymeric substance matrix-a modelling study. Microbiology 151, 3817-3832.

Xue, Z., Sendamangalam, V.R., Gruden, C.L., Seo, Y., 2012. Multiple roles of extracellular polymeric substances on resistance of biofilm and detached clusters. Environ. Sci. Technol. 46, 13212-13219.

Zhou, L.-l., Zhang, Y.-j., Li, G.-b., 2009. Effect of pipe material and low level disinfectants on biofilm development in a simulated drinking water distribution system. J. Zhejiang Univ.-Sci. A 10, 725-731. 